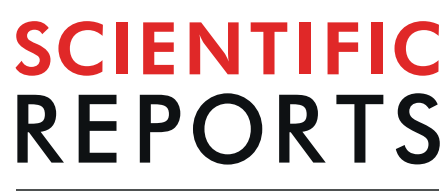

natureresearch

\title{
OPEN A highly-selective chloride microelectrode based on a mercuracarborand anion carrier
}

\author{
Marino DiFranco ${ }^{1}$, Marbella Quinonez ${ }^{1}$, Rafal M. Dziedzic ${ }^{2}$, Alexander M. Spokoyny ${ }^{2,3}$ \& \\ Stephen C. Cannon ${ }^{1 *}$
}

The chloride gradient plays an important role in regulating cell volume, membrane potential, $\mathrm{pH}$, secretion, and the reversal potential of inhibitory glycine and $G A B A_{A}$ receptors. Measurement of intracellular chloride activity, $a_{C l}^{i}$ using liquid membrane ion-selective microelectrodes (ISM), however, has been limited by the physiochemical properties of $\mathrm{Cl}^{-}$ionophores which have caused poor stability, drift, sluggish response times, and interference from other biologically relevant anions. Most importantly, intracellular $\mathrm{HCO}_{3}^{-}$may be up to 4 times more abundant than $\mathrm{Cl}^{-}$(e.g. skeletal muscle) which places severe constraints on the required selectivity of a $\mathrm{Cl}^{-}-$sensing ISM. Previously, a sensitive and highly-selective $\mathrm{Cl}^{-}$sensor was developed in a polymeric membrane electrode using a trinuclear $\mathrm{Hg}$ (II) complex containing carborane-based ligands, [9]-mercuracarborand-3, or MC3 for short. Here, we have adapted the use of the MC3 anion carrier in a liquid membrane ion-selective microelectrode and show the MC3-ISM has a linear Nernstian response over a wide range of $a_{C l}(0.1 \mathrm{mM}$ to $100 \mathrm{mM})$, is highly selective for $\mathrm{Cl}^{-}$over other biological anions or inhibitors of $\mathrm{Cl}^{-}$transport, and has a $10 \%$ to $90 \%$ settling time of $3 \mathrm{sec}$. Importantly, over the physiological range of $a_{C I}(1 \mathrm{mM}$ to $100 \mathrm{mM})$ the potentiometric response of the MC3-ISM is insensitive to $\mathrm{HCO}_{3}^{-}$or changes in pH. Finally, we demonstrate the biological application of an MC3-ISM by measuring intracellular $a_{C l}$ and the response to an external CIfree challenge, for an isolated skeletal muscle fiber.

Chloride ions $\left(\mathrm{Cl}^{-}\right)$are the major inorganic free anions of the extracellular fluid, and together with organic bicarbonate ions $\left(\mathrm{HCO}_{3}^{-}\right)$are the major intracellular anions $s^{1,2}$. The transmembrane $\mathrm{Cl}^{-}$gradient has a critical role in multiple cellular processes including cell volume regulation, acid-base homeostasis, fluid and electrolyte secretion, membrane excitability and the reversal potential of glycine and $\mathrm{GABA}_{\mathrm{A}}$-receptors at inhibitory synapses (see ${ }^{1}$ and references therein). Moreover, the $\mathrm{Cl}^{-}$gradient is dynamic in many cells. For example, a developmental change in the expression of cation/chloride co-transporters reduces $\left[\mathrm{Cl}^{-}\right]_{\mathrm{i}}$ in mature neurons, and thereby converts $\mathrm{GABA}_{\mathrm{A}}$-receptor mediated responses from excitatory to inhibitory by shifting $E_{C l}$ to more negative potentials ${ }^{3}$. The steady-state $\mathrm{Cl}^{-}$gradient is determined by the balance of both passive transport, through ion channels as determined by the $\mathrm{Cl}^{-}$electrochemical potential, and by secondary active mechanisms via coupling to exchangers or cotransporters.

We sought a method to measure the $\mathrm{Cl}^{-}$gradient across the sarcolemma of skeletal muscle, where the resting potential $\left(V_{\text {rest }}\right)$ is strongly dependent on the $\mathrm{Cl}^{-}$driving force, $V_{m}-E_{C \text { l }}$, because these cells have a remarkably high resting chloride conductance $\left(g_{C l} \sim 1 \mathrm{mS} / \mathrm{cm}^{2}\right)^{4,5}$. Moreover, shifts of the sarcolemmal $\mathrm{Cl}^{-}$gradient have been causally implicated in attacks of periodic paralysis ${ }^{6,7}$. Understanding the roles of $\mathrm{Cl}^{-}$in muscle physiology, and all cells in general, demands knowing its concentration in the intra- and extracellular milieus, or more properly its activity $\left(a_{C l}\right)$ or "effective concentration", that ultimately determines the physiochemical reactivity of $\mathrm{Cl}^{-8}$.

While measuring the extracellular $a_{C l}^{o}$ is relatively easy, non-destructive measurements of intracellular $a_{C l}^{i}$ poses major challenges. Basically, two methods are available to assess the intracellular chloride activity: (1) micro-photometric techniques, using either chemical or optogenetic $\mathrm{Cl}^{-}$sensors ${ }^{9,10}$ and (2) potentiometric techniques with liquid membrane ion-selective microelectrodes (ISM for short) ${ }^{11,12}$. Photometric techniques allow for specific, high time resolution and space-resolved determination of changes in the activity of physiologically relevant ions, e.g. $\mathrm{Ca}^{2+}, \mathrm{Na}^{+}, \mathrm{K}^{+}, \mathrm{H}^{+}, \mathrm{Cl}^{-}$. However, activity-dependent changes in optical properties of sensors are

${ }^{1}$ Department of Physiology, David Geffen School of Medicine at UCLA, Los Angeles, California, USA. ${ }^{2}$ Department of Chemistry and Biochemistry, UCLA, Los Angeles, California, USA. ${ }^{3}$ California NanoSystems Institute (CNSI), UCLA, Los Angeles, California, USA. *email: sccannon@mednet.ucla.edu 
usually difficult to de-convolve into accurate molar units, and in some conditions, sensors can alter the extent and kinetics of the ion concentration changes aimed to be measured. Fluorescence life-time imaging circumvents some of these challenges ${ }^{9}$, but requires specialized and expensive detection systems. In principle, an ISM is devoid of these limitations, and is expected to provide a direct determination of intracellular activity. In fact, ISMs are often used to measure the activities of ions in solutions that are used to calibrate photometric sensors. On the other hand, ISMs cannot track fast changes in ion activity (i.e. in the ms range, but see ${ }^{13,14}$ ) and in some cases selectivity is a limiting factor. The key component of an ISM is the ion-selective carrier or ionophore, which endows the electrode with the selectivity required to discriminate between ions of similar nature and the sensitivity (usually down to the sub-micromolar range). In contrast to the case for cations, there is a general lack of highly-selective naturally occurring or synthetic anion ionophores, and in particular for $\mathrm{Cl}^{-15,16}$.

We tested ISMs made with several commercially available $\mathrm{Cl}^{-}$ionophores, and unlike our experience with cation ionophores $\left(\mathrm{H}^{+}, \mathrm{Na}^{+}\right)$we found their responses far from ideal. These $\mathrm{Cl}^{-}$ionophores included: tributyltin (TBT), chloride ionophores I-IV (Selectophore ${ }^{\mathrm{TM}}$, Millipore-Sigma), and the antibiotic 3,4,4'trichlorocarbanilide ${ }^{17}$. We found ISMs fabricated with these compounds had one or more of the following problems: lack of linearity, sub- or supra-Nernstian responses, drift, hysteresis, poor solubility in liquid membranes, sensitivity to blockers of chloride channels or transporters, and poor selectivity for $\mathrm{Cl}^{-}$over $\mathrm{HCO}_{3}^{-}$. We also tested a chemically diverse group of recently published compounds described as $\mathrm{Cl}^{-}$carriers for biological membranes: compound- $1^{18}$, compound $4 \mathrm{H}^{19}$, cholapod-3, and decalin-13 $16,20,21$, and found them not appropriate to build ISMs, mostly demonstrating solubility problems.

Here we report that a $\mathrm{Cl}$-selective anion carrier based on a trinuclear $\mathrm{Hg}(\mathrm{II})$ complex containing carborane-based ligands, [9]mercuracarborand-3 (MC3), that was previously used in polymer membrane $\mathrm{Cl}^{-}$ sensors $^{22}$ is also ideal for liquid membrane Cl-selective ISMs. MC3 is a macrocyclic structure bearing a pre-organized Lewis acid cavity that selectively complexes with $\mathrm{Cl}^{-}$and functions as an anion carrier in the liquid membrane ISM. We show the MC3-ISM is highly selective for $\mathrm{Cl}^{-}$over other biologically relevant anions $\left(\mathrm{HCO}_{3}^{-}\right.$, lactate, $\mathrm{PO}_{4}^{-}$) and is insensitive to $\mathrm{Cl}$-channel blockers (9-anthracene carboxylic acid), inhibitors of cation-chloride co-transporters (bumetanide, furosemide), or changes in $\mathrm{pH}$ and is therefore well-suited for biophysical applications to quantitatively and accurately measure $a_{C l}^{i}$.

\section{Methods}

MC3 synthesis. To our knowledge, [9]mercuracarborand-3 (MC3, CAS Registry Number 146219-95-6) is not commercially available and so it was synthesized using air-free Schlenk techniques as described by Hawthorne and co-workers ${ }^{23}$. An oven dried Schlenk flask was charged with $144 \mathrm{mg}(0.5 \mathrm{mmol})$ of ortho-carborane (Boron Specialties), filled with an $\mathrm{N}_{2}$ atmosphere, and $5 \mathrm{~mL}$ of anhydrous diethyl ether $\left(\mathrm{Et}_{2} \mathrm{O}\right)$ (Fisher, inhibitor free) were added via syringe. The reaction vessel was cooled to $0^{\circ} \mathrm{C}$ using an ice bath, $0.85 \mathrm{~mL}$ of $2.5 \mathrm{M} \mathrm{n}$-BuLi in hexane (Sigma-Aldrich) was added dropwise to the rapidly stirring reaction mixture. After addition of the n-BuLi solution, the ice bath was removed and the reaction was stirred at room temperature for 2 hours. Next, $315 \mathrm{mg}$ of $\mathrm{Hg}(\mathrm{OAc})_{2}$ (Mallinckrodt) was added to the reaction mixture under a flow of $\mathrm{N}_{2}$ and the reaction mixture was stirred at room temperature for 16 hours. Upon completion of the reaction, the reaction was quenched with $5 \mathrm{~mL}$ of $\mathrm{H}_{2} \mathrm{O}$, the organic layer was collected, the aqueous portion was extracted with $5 \mathrm{~mL} \mathrm{Et}_{2} \mathrm{O}$. The organic portions were combined and washed with $5 \mathrm{~mL} \mathrm{H}_{2} \mathrm{O}$, then the organic layer was dried with $\mathrm{MgSO}_{4}$ and filtered through $2 \mathrm{~cm}$ of silica gel using $\mathrm{Et}_{2} \mathrm{O}$ as the eluent. The filtrate was evaporated to dryness using a rotary evaporator to yield a white solid. Due to difficulty with purifying the product by recrystallization from $\mathrm{Et}_{2} \mathrm{O}$, an alternative purification method was developed as follows. The white solid was washed with hexanes, dissolved in $10 \mathrm{~mL}$ of $20 \%(\mathrm{v} / \mathrm{v})$ hexanes in $\mathrm{Et}_{2} \mathrm{O}$ and left in a fume hood to evaporate the $\mathrm{Et}_{2} \mathrm{O}$ portion which resulted in precipitation of an offwhite powder. The supernatant was decanted and the solids were loaded onto a $3 \mathrm{~cm}$ plug of silica gel wetted with $40 \%$ acetone $(\mathrm{v} / \mathrm{v})$ in hexanes and eluted with $40 \%$ acetone $(\mathrm{v} / \mathrm{v})$ in hexanes. The resulting filtrate was evaporated to dryness to yield $50 \mathrm{mg}$ ( $14 \%$ yield) of an off-white solid which contains $>95 \% \mathrm{MC} 3$ by ${ }^{11} \mathrm{~B}$ NMR. ${ }^{1} \mathrm{H}$ NMR $\left(400 \mathrm{MHz},\left(\mathrm{CD}_{3}\right)_{2} \mathrm{CO}\right) \delta 3.0-1.2(\mathrm{~m}) .{ }^{11} \mathrm{~B} \mathrm{NMR}\left(160 \mathrm{MHz},\left(\mathrm{CD}_{3}\right)_{2} \mathrm{CO}\right) \delta 1.6(\mathrm{~d}, 2 \mathrm{~B}),-5.4(\mathrm{~d}, 2 \mathrm{~B}),-8.0(\mathrm{~d}, 6 \mathrm{~B})$.

Micropipette silanization. Micropipettes were pulled from $1.5 \mathrm{~mm}$ borosilicate capillaries with micro-filaments (BF150-86-10, Sutter Instruments). A 4-step pulling protocol was optimized to obtain a short taper $(\sim 8 \mathrm{~mm})$ leading to a sub-micron tip opening, using a horizontal puller (P97, Sutter Instruments). When filled with a saline mimicking the ion composition of myoplasm (see solutions), the microelectrodes had tip resistances of 10-12 $\mathrm{M} \Omega$. The use of capillaries with micro-filaments greatly reduced the filling-time in the manufacture of ISMs ( $\sim 5 \mathrm{~min}$ compared to $>30 \mathrm{~min}$ for plain capillaries), without compromising the sealing of the organic phase to the inner surface of the capillary wall. Capillaries were silanized as supplied from the vendor, with no pre-treatment.

For silanization, micropipettes were laid horizontally on a support in a Pyrex glass jar (with lid, $\sim 500 \mathrm{ml}$ ). One hundred $\mu \mathrm{l}$ of chlorotrimethylsilane (Sigma) was placed in the jar and allowed to evaporate at RT for $\sim 5 \mathrm{~min}$. The silane vapor had free access to a micropipette's interior and exterior surfaces. Then, the micropipettes were baked at $250^{\circ} \mathrm{C}$ for at least $4 \mathrm{~h}$ (usually overnight). As occurs with all liquid-junction microelectrodes, silanization was essential to insure the mechanical stability and high electrical resistance between the hydrophobic liquid membrane and the inner wall of an ISM. Silanized micropipettes were stored dry in a closed jar (WPI Jar-E215) to avoid dust adhesion, and were used for up 2 weeks with no noticeable deterioration.

$\mathrm{Cl}^{-}$sensing liquid membrane and ISM half-cell saline. The ISM liquid membrane consisted of a short column $(200-300 \mu \mathrm{m})$ of a hydrophobic "chloride cocktail" lodged in the tip of the micropipette. The chloride cocktail was made by dissolving the MC3 and a lipophilic cationic additive (tridodecylmethyl ammonium chloride, TDMAC, Sigma) in the water - immiscible organic solvent 2-nitrophenyl octyl ether (NPOE, Sigma). We 
used 10\% MC3 and 2.5\% TDMAC in NPOE (w/volume). No other mixing ratios or solvents were studied. The ISM half-cell consisted of $100 \mathrm{mM} \mathrm{NaCl}$, backfilled into the microelectrode and in contact with an $\mathrm{Ag} / \mathrm{AgCl}$ reversible electrode.

ISM fabrication. We devised a simple and efficient method to fabricate ISMs. Starting with previously silanized micropipettes, we routinely made six ISMs in less than $1 \mathrm{~h}$. To fabricate an MC3-ISM both the chloride cocktail and the reference saline were sequentially backfilled into the micropipette, while viewing under a stereomicroscope. First, an excess amount of chloride cocktail (2-3 times the final volume of the liquid membrane) was delivered as close as possible to the micropipette tip using a $34 \mathrm{G}$ microneedle (Quickfil 34G-5, WPI, for which the polyimide coating was stripped from the end). The organic phase spontaneously moves towards the tip of the micropipette by capillary action and fills the shaft in 3-5 min. Initially using excess chloride cocktail speeds up this filling step. Once the tip is filled, the chloride cocktail volume is reduced as much as possible by suction with a new $34 \mathrm{G}$ needle. Finally, the saline solution is delivered (using another $34 \mathrm{G}$ needle), assuring that a clean interface is formed between the two liquids. Care must be taken to avoid air bubbles in the organic phase or interface, otherwise the ISM should be discarded.

Prior to use, each MC3-ISM was individually tested using a 3 point calibration including solutions of 1, 10 and $100 \mathrm{mM} \mathrm{Cl}$ (see solutions), with $a_{C l}$ of $0.64,6.46$, and $68.5 \mathrm{mM}$ respectively. Tested MC3-ISMs were stored in closed jars (to avoid evaporation and dust) with tips submersed in a filtered $(0.2 \mu \mathrm{m})$ solution containing $10 \mathrm{mM}$ $\mathrm{NaCl}$; and could be used after 1-2 weeks from fabrication with no detectable deterioration.

Measurement of ISM potential. A two-channel high input impedance $\left(>10^{15} \Omega\right)$ amplifier (FD223a, WPI) was used to measure the electrical potential of MC3-ISMs. One channel was connected to the Ag/ $\mathrm{AgCl}$ wire of an MC3-ISM. The second channel was connected to a standard ("sharp") microelectrode having $10-15 \mathrm{M} \Omega$ tip resistance when filled with electrode solution (see solutions). This microelectrode served as a reference electrode, whose value $\left(\mathrm{V}_{\text {ref }}\right)$ reflects changes in junction potential that may occur upon solution exchanges. Three amplifier outputs, $V_{\text {ref }}, V_{\text {ISM }}$, and the analog difference $V_{\text {ISM }}-V_{\text {ref }}$ were digitized with a 16-bit $A / D$ converter and stored on a computer (LabVIEW, National Instruments). The figures show $\mathrm{V}_{\mathrm{C}}$, defined as $-\left(\mathrm{V}_{\mathrm{ISM}}-\mathrm{V}_{\text {ref }}\right)$, because with this sign convention the potentiometric signal increases for an increase in $a_{C l}$.

Solutions. Solutions containing different $\left[\mathrm{Cl}^{-}\right]$were prepared in two ways: (1) Calibration solutions devoid of any possible interfering anion were prepared by serially diluting a pure $\mathrm{NaCl}$ solution with distilled water (18 M $\Omega-\mathrm{cm}$, Millipore). (2) Calibration solutions suitable for use with mammalian cells were prepared by mixing two solutions having a composition similar to that of Tyrode's buffer but differing in the main anion content, and having the same $\mathrm{pH}$ and divalent cation content. These solutions differ in that one (150- $\mathrm{Cl}$ solution) contained $\mathrm{Cl}^{-}$as the main anion, and the other $\left(0-\mathrm{Cl}\right.$ solution) was devoid of $\mathrm{Cl}^{-}$, and contained $\mathrm{SO}_{4}^{-2}$ as the main anion. Both solutions have HEPES (a possible interfering anion) as the $\mathrm{pH}$ buffer.

$$
\begin{gathered}
\text { 150-Cl solution }(m M): \begin{array}{l}
140 \mathrm{NaCl}, 4 \mathrm{KCl}, 2 \mathrm{CaCl}_{2}, 1 \mathrm{MgCl}_{2}, 10 \mathrm{HEPES} ; \\
\mathrm{pH}=7.4 \text { with } \mathrm{NaOH} .
\end{array} \\
0-C l \text { solution }(m M): \begin{array}{l}
115 \mathrm{Na}_{2} \mathrm{SO}_{4}, 2 \mathrm{~K}_{2} \mathrm{SO}_{4}, 2 \mathrm{Ca}(\mathrm{OH})_{2}, 1 \mathrm{Mg}(\mathrm{OH})_{2}, 10 \text { HEPES; } \\
\mathrm{pH}=7.4 \text { with } \mathrm{H}_{2} \mathrm{SO}_{4} .
\end{array}
\end{gathered}
$$

Calibration solutions containing from $100 \mathrm{mM}$ to $10 \mathrm{nM}$ nominal $\mathrm{Cl}$ concentrations were made by serial dilutions of the $150-\mathrm{Cl}$ solution with the $0-\mathrm{Cl}$ solution.

Solutions containing potential interfering anions were prepared by adding $10 \mathrm{mM}$ of Na-lactate, $\mathrm{NaHCO}_{3}$, $\mathrm{Na}_{2} \mathrm{HPO}_{4}$ or $\mathrm{NaSCN}$ to a mixture of the $150-\mathrm{Cl}$ and $0-\mathrm{Cl}$ solutions, and then performing a similar serial dilution as described above to obtain the desired $\left[\mathrm{Cl}^{-}\right]$. Drug-containing solutions were made from highly concentrated stock solutions of 9-anthracenecarboxylic acid (9-ACA, $500 \mathrm{mM}$ in DMSO) or bumetanide (BMT, $50 \mathrm{mM}$ in DMSO). DMSO final concentration was kept below 1:1000, and controls were run to exclude direct effects of solvent.

Solutions used for recording from isolated mouse muscle fibers were either standard (i.e. Cl-containing) Tyrode's solution or Cl-free Tyrode's in which the $\mathrm{Cl}^{-}$was replaced with $\mathrm{SO}_{4}^{-}$. Standard Tyrode's (mM): $150 \mathrm{NaCl}$, $4 \mathrm{KCl}, 2 \mathrm{CaCl}_{2}, 1 \mathrm{MgCl}_{2}, 10$ glucose, 10 HEPES; $\mathrm{pH}=7.4$ with $\mathrm{NaOH}$. Cl-free Tyrode's $(\mathrm{mM}): 115 \mathrm{Na}_{2} \mathrm{SO}_{4}, 2$ $\mathrm{K}_{2} \mathrm{SO}_{4}, 2 \mathrm{Ca}(\mathrm{OH})_{2}, 1 \mathrm{Mg}(\mathrm{OH})_{2}, 10$ HEPES; $\mathrm{pH}=7.4$ with $\mathrm{H}_{2} \mathrm{SO}_{4}$. A salt bridge was used to connect the bath of the recording chamber to the reference ground, so that shifts in the junction potential were minimized when bath exchanges were used.

The MC3-ISM was backfilled with a solution containing (in $\mathrm{mM}$ ): $100 \mathrm{NaCl}, 10 \mathrm{HEPES}, \mathrm{pH}=7.4$ with $\mathrm{H}_{2} \mathrm{SO}_{4}$. The reference (bath) and intracellular microelectrodes were filled with a solution (in $\mathrm{mM}$ ): $60 \mathrm{~K}$-aspartate, 5 di-Na ATP, 5 di-tris creatine phosphate, 40 EGTA, 20 MOPS, $5 \mathrm{MgCl}_{2}, \mathrm{pH}=7.4$ with $\mathrm{KOH}$.

All chemicals were purchased and used as received from Millipore-Sigma, unless otherwise noted (vide supra).

$\mathrm{Cl}^{-}$activity calculation $\left(\boldsymbol{a}_{\boldsymbol{C l}}\right)$. The value for the activity of an ion in solution, $a_{i o n}$ is often obtained from tables ${ }^{24}$, but these values were calculated from solutions of single salts (e.g. $\mathrm{NaCl}, \mathrm{KCl}$ ). Instead, we calculated $a_{C l}$ (in $\mathrm{mM}$ ) for all simple and mixed solutions as: $a_{C l}=\gamma_{C l} *[C l]$, where $\gamma_{C l}$ is the chloride activity coefficient (dimensionless). The activity coefficient was calculated from the extended Debey-Hückel ${ }^{25}$ formalism as: 

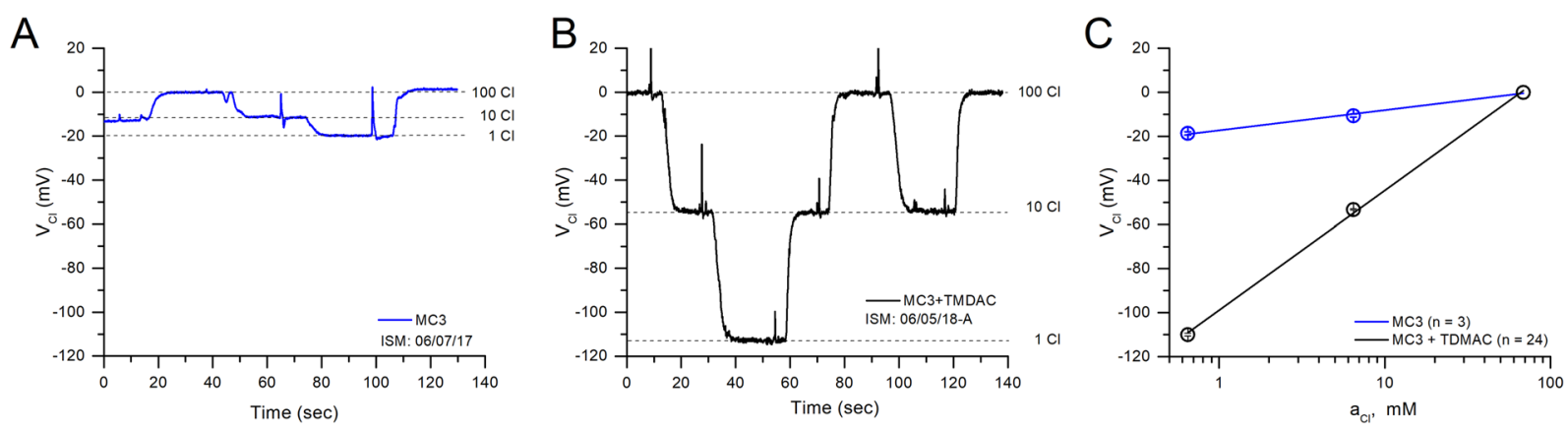

Figure 1. TDMAC is required for Nernstian behavior of the MC3-ISM. (A) Response of an exemplary ISM for which the liquid membrane consisted only of $10 \% \mathrm{MC} 3$ dissolved in NPOE, as the $\left[\mathrm{Cl}^{-}\right]$was varied from 1 to $100 \mathrm{mM}$. (B) Response of another ISM containing the same liquid membrane as in A, but supplemented with $2.5 \%$ TDMAC. The rapid transients for the tracings in $(\mathbf{A}, \mathbf{B})$ were caused by solution switching and suction-dependent fluctuations. $(\mathbf{C})$ Plot of $\mathrm{V}_{\mathrm{Cl}}$ as a function of $\log _{10}\left(a_{C l}\right)$ shows a linear relation with a slope of $54.6 \pm 0.18 \mathrm{mV}(\mathrm{n}=24)$ for the ISMs containing TDMAC (black circles), as expected for a Nernstian response. For ISMs lacking TDMAC (blue circles), a sub-Nernstian response was observed with a slope of $9.2 \pm 0.67 \mathrm{mV}$ $(n=3)$. The error bars for the SEM are very small, and obscured by the symbols.

$$
\log \left(\gamma_{C l}\right)=\frac{-A z_{i}^{2} \sqrt{I s}}{1+B \delta_{C l} \sqrt{I s}}
$$

where $\delta_{C l}$ is the effective $\mathrm{Cl}^{-}$ion diameter $(0.3 \mathrm{~nm}), A=-0.510$, and $B=3.29$. The ionic strength, $I s$, of a solution containing many ions, $i_{i} n_{i}$, with valences $z_{i}$ was calculated as:

$$
I s=\frac{1}{2} \sum_{i}\left[\text { ion }_{i}\right] z_{i}^{2}
$$

"In cuvette" MC3-ISM characterization. A small circular plastic experimental chamber (8 mm in diameter, $1 \mathrm{~mm}$ depth, $\sim 0.5 \mathrm{ml}$ in volume) was used to study the response of MC3-ISMs to $\left[\mathrm{Cl}^{-}\right]$changes and to determine selectivity. The chamber was continuously perfused with the test solution of choice and the entire chamber could be completely exchanged in $\sim 1 \mathrm{sec}$. Perfusion flux (standard of $1-2 \mathrm{ml} / \mathrm{min}$ ) was driven by gravity and the efflux was removed by aspiration, keeping the level of solution constant to minimize drifts in junction potentials. The chamber solution was connected to ground via a salt bridge $(3 \%$ agar in $125 \mathrm{mM} \mathrm{KCl}$, w/v containing a floating platinum wire) in contact with a $125 \mathrm{mM} \mathrm{KCl}$ solution and an $\mathrm{Ag} / \mathrm{AgCl}$ electrode. This arrangement represented the second (electrical) half-cell across the MC3-ISM's liquid membrane.

Muscle fiber ISM measurements. To test the MC3-ISM in a cellular context, we used enzymatically dissociated skeletal muscle fibers from the flexor digitorum brevis (FDB) of the mouse, as previously described ${ }^{26}$. All mouse procedures were approved by the University of California Los Angeles Institutional Animal Care and Use Committee. All methods performed in this study were conducted in accordance with the guidelines and regulations of the IACUC. Fibers were plated in the same chamber as above, and impaled with a MC3-ISM and a reference micro-electrode. Before impalement, both MC3-ISM and reference micro-electrode were zeroed in the presence of $100-\mathrm{Cl}$ Tyrode.

Selectivity coefficient, $\boldsymbol{K}_{\mathrm{Cl}, \boldsymbol{X}}^{\text {pot }}$. The relative selectivity of an MC3-ISM for $\mathrm{Cl}^{-}$over a test interfering anion was determined by the fixed interference method ${ }^{27}$. The concentration of the test interfering anion, $\left[\mathrm{X}^{-}\right]$, was maintained at a fixed value of $10 \mathrm{mM}$, and the MC3-ISM / potential was measured as the $\left[\mathrm{Cl}^{-}\right]$was varied from $10 \mathrm{nM}$ to $100 \mathrm{mM}$. The MC3-ISM potential was plotted against $\log \left(a_{C l}\right)$ and the intersection of the two linear portions (Nernstian for high $\left[\mathrm{Cl}^{-}\right]$and saturating for low $\left[\mathrm{Cl}^{-}\right]$) determined the value of $a_{C l}$ that was used to calculate the selectivity coefficient for $\mathrm{Cl}^{-}$over $\mathrm{X}^{-}$as:

$$
K_{C l, X}^{p o t}=a_{C l} / a_{X}^{z_{C l}} z_{X} .
$$

Values are reported as the mean \pm standard error of the mean.

\section{Results}

A cationic additive increases the $\mathrm{Cl}^{-}$responsiveness an MC3-based ISM. We first tested the response of liquid membrane ISMs constructed using a cocktail containing only MC3 (10\%) and NPOE. These electrodes were only weakly sensitive to $\left[\mathrm{Cl}^{-}\right]$changes, as shown for an exemplary response in Fig. 1A. This response is sub-Nernstian, with a slope of $9.2 \pm 0.67 \mathrm{mV} /$ decade $(\mathrm{n}=3)$ on a plot of $\mathrm{V}_{\mathrm{Cl}}$ as a function of $\log _{10}\left(a_{C l}\right)$ (Fig. 1C, blue symbols). This result is in agreement with previous data ${ }^{22}$, demonstrating that polymeric membranes containing $\mathrm{MC} 3$ are insensitive to $\mathrm{Cl}^{-}$unless the membranes are doped with cationic compounds. 
A

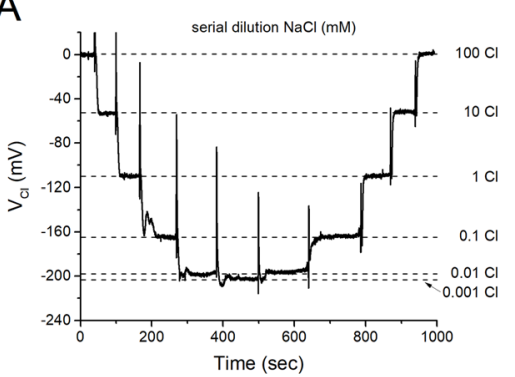

B

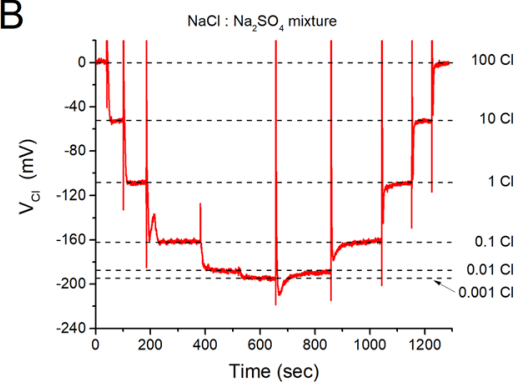

C

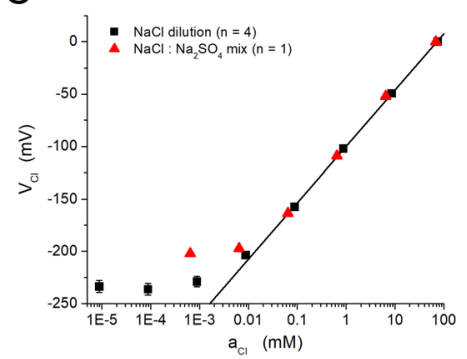

Figure 2. MC3-ISMs have a linear response to $\left[\mathrm{Cl}^{-}\right]$changes from 0.1 to $100 \mathrm{mM}$. (A) Continuous record of the response $\left(\mathrm{V}_{\mathrm{Cl}}\right)$ for an MC3-ISM exposed to solutions of various $\left[\mathrm{Cl}^{-}\right]$from $0.001 \mathrm{mM}$ to $100 \mathrm{mM}$, obtained by serial dilutions of a $100 \mathrm{mM} \mathrm{NaCl}$ solution with water. (B) Continuous record of another MC3-ISM exposed to the same nominal $\left[\mathrm{Cl}^{-}\right]$, but obtained by mixing $\mathrm{Cl}$-based and $\mathrm{SO}_{4}$-based solutions (see Methods). The dashed lines in $(\mathbf{A}, \mathbf{B})$ represent the steady state values of the ISMs at the indicated $\left[\mathrm{Cl}^{-}\right]$. (C) The steady-state $\mathrm{V}_{\mathrm{Cl}}$ is plotted as a function of $a_{C}$, which was calculated on the basis of the ionic strength of the test solutions (See Methods). A linear fit of $\mathrm{V}_{\mathrm{Cl}}$ as a function of $a_{C l}$ over a range from 0.088 to $75 \mathrm{mM}$, for the dilution method, had a slope of $52.8 \pm 0.63 \mathrm{mV} /$ decade $(\mathrm{n}=4$, straight line $)$.

When the liquid membrane cocktail was supplemented with a lipophilic cationic additive, TDMAC (2.5\%, $\mathrm{w} / \mathrm{w}$ ), the potentiometric response became highly sensitive to $\left[\mathrm{Cl}^{-}\right]$changes between 1 and $100 \mathrm{mM}$ (Fig. 1B). For brevity, we refer to microelectrodes with this complete liquid membrane cocktail as MC3-ISMs, but it should be recognized they are doped with TDMAC. The voltage response of MC3-ISMs was stable and showed no signs of hysteresis. Over this range of $\left[\mathrm{Cl}^{-}\right]$, the MC3-ISM response was nearly Nernstian, with a slope of $54.6 \pm 0.18 \mathrm{mV} /$ decade $(\mathrm{n}=24)$, as shown in Fig. 1C (black symbols). The reference electrode had very small voltage changes in response to these solution exchanges $\left(2-3 \mathrm{mV}\right.$, not shown), and these small deviations were subtracted from $\mathrm{V}_{\text {ISM }}$ to obtain $\mathrm{V}_{\mathrm{Cl}}$ values shown in Fig. 1 .

We did not explore other combinations of MC3 and TDMAC since the $10 \%$ and $2.5 \%(\mathrm{w} / \mathrm{w})$, respectively, mixture tested gave optimal results. The need for a lipophilic cation stems from the fact that MC3 is a neutral carrier, and as such it is expected to produce a limited anion response unless a counterion for the mercuracarborand complex is added ${ }^{22}$.

Linearity and $\mathrm{Cl}^{-}$detection limit of the MC3-ISM. The linear range for $\mathrm{Cl}^{-}$responsiveness of the MC3-ISM was determined by changing the $\left[\mathrm{Cl}^{-}\right]$over 7 orders of magnitude, in ten-fold steps from $100 \mathrm{mM}$ to $10 \mathrm{nM}$. This calibration was performed with solutions prepared by serial dilution of $100 \mathrm{mM} \mathrm{NaCl}$ with water (Methods) to minimize the possibility of interfering anions at low concentrations of $\mathrm{Cl}^{-}$. A typical continuous recording of $\mathrm{V}_{\mathrm{Cl}}$ during the decrease and then increase of $\left[\mathrm{Cl}^{-}\right]$is shown in Fig. $2 \mathrm{~A}$. Jumps of $\mathrm{V}_{\mathrm{Cl}}$ to new stable values are clearly evident with each solution exchange, and the dotted lines emphasize that no hysteresis was detected. The change in $\mathrm{V}_{\mathrm{Cl}}$ became compressed (i.e. smaller jumps) for test solutions of less than $0.1 \mathrm{mM}\left[\mathrm{Cl}^{-}\right]$, as the linear range was exceeded.

A limited number of trials were also performed with solutions prepared by serially diluting $100 \mathrm{mM} \mathrm{NaCl}$ with a $\mathrm{Na}_{2} \mathrm{SO}_{4}$-based solution (Fig. $2 \mathrm{~B}$ ) that is commonly used for "chloride-free" conditions in studies on skeletal muscle fibers (Methods, 0 - Cl solution). This alternative method maintains a high ionic strength for all test values of $\left[\mathrm{Cl}^{-}\right]$and provides a check for evidence of interfering anions in a mammalian physiologic buffer. A plot of steady-state $\mathrm{V}_{\mathrm{Cl}}$ as a function of $\log _{10}\left(a_{C l}\right)$ shows that between $0.1 \mathrm{mM}$ and $100 \mathrm{mM}$ the response was linear (Fig. 2C). This range exceeds the expected values of intracellular $a_{C l}$ to be encountered in mammalian cells (3 to $20 \mathrm{mM}$, or even up to $100 \mathrm{mM}$ in pathological contexts such as glioma ${ }^{28}$ ). Moreover, the response for dilutions with pure water was near-linear down to an activity of $0.01 \mathrm{mM}$. The saturation of $\mathrm{V}_{\mathrm{Cl}}$ at about $-200 \mathrm{mV}$ for the $\mathrm{NaCl}: \mathrm{Na}_{2} \mathrm{SO}_{4}$ mixture reveals an interfering anion effect of $\mathrm{SO}_{4}^{-2}$, although this was detectable only at low $a_{C l}$ levels $(<0.1 \mathrm{mM})$ that are not encountered in cells.

The average slope of the linear response range was $52.8 \pm 0.63 \mathrm{mV} /$ decade $(\mathrm{n}=14)$. While this slope is slightly smaller than the theoretical value of $58 \mathrm{mV}$, it is comparable to values reported for MC3 electrodes fabricated in solid membranes ${ }^{22}$. Those electrodes also showed a sub-Nernstian response, with the slope being smaller for lower molar ratios of TDMAC to MC3.

The settling time for an MC3-ISM is a few seconds. Another desirable feature of ISMs for biological applications is a small time constant. To assess the time response of the MC3-ISM, we increased the flow rate of the solutions perfusing the experimental chamber $(40 \mathrm{ml} / \mathrm{min})$, as compared with those used in experiments in Figs. 1 and 2. The continuous flow was briefly switched from a $100 \mathrm{mM} \mathrm{Cl}^{-}$solution to a $10 \mathrm{mM} \mathrm{Cl}^{-}$solution that also contained fluorescein $(100 \mu \mathrm{M})$. Local spot illumination $(100 \mu \mathrm{m}$ diameter disc, $\lambda=488 \mathrm{~nm})$ near the tip of the MC3-ISM was used to simultaneously measure the kinetics of the bath exchange while the MC3-ISM response was recorded. On average, the fluorescence transient decayed with a time constant of $1.1 \pm 0.15 \mathrm{sec}$ $(\mathrm{n}=4)$ and after a brief lag, $V_{C l}$ decayed almost as quickly, $1.4 \pm 0.26 \mathrm{sec}(\mathrm{n}=4)$, as shown by the exemplary responses in Fig. 3. Thus even at this high flow rate, the response time of our MC3-ISM is limited by solution exchange, and we can conclude that the intrinsic time constant of the ISM is smaller than $1.4 \mathrm{sec}$. 


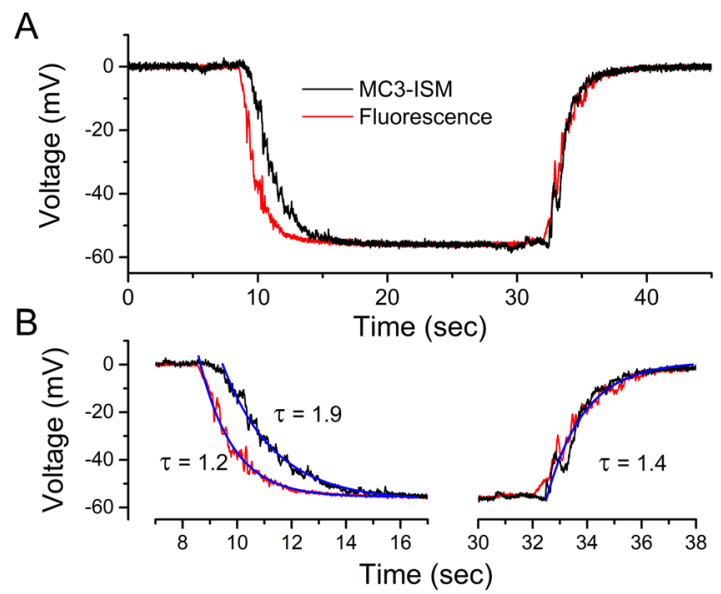

Figure 3. Liquid-membrane MC3-ISMs respond rapidly to $\left[\mathrm{Cl}^{-}\right]$changes. (A) Simultaneous recording of $V_{C l}$ and the solution exchange, when the continuous flow of $100 \mathrm{mM} \mathrm{Cl}^{-}$was briefly switched to $10 \mathrm{mM} \mathrm{Cl}^{-}(9$ to $33 \mathrm{sec}$ interval) and back. Flow was detected by adding fluorescein $(100 \mu \mathrm{M})$ to the $10 \mathrm{mM} \mathrm{Cl}^{-}$solution and exciting with local spot illumination $(100 \mu \mathrm{m}$ disc) near the ISM tip. Signals were sampled at $50 \mathrm{~Hz}$, and the amplitude of the fluorescence signal was scaled to provide a direct comparison of kinetics by superimposing the traces. (B) Onset and offset of the $10 \mathrm{mM} \mathrm{Cl}^{-}$exchange are shown on an expanded time scale, along with exponential fits.

The response time of a liquid-junction ISM is usually faster as the width of the organic phase decreases at the tip of the electrode ${ }^{13,14}$. The width for the liquid membrane of our MC3-ISMs was $\sim 300 \mu \mathrm{m}$, and we did not explore whether the time constant could be reduced by decreasing the width of the organic phase. In any event, a time response in the order of a few seconds is sufficient to study intracellular $\left[\mathrm{Cl}^{-}\right]$changes expected to occur in several tens of second to minutes in biological settings.

The MC3-ISM is insensitive to changes in $\mathrm{pH}$ or $\mathrm{HCO}_{3}^{-}$. One of the biggest drawbacks of available $\mathrm{Cl}^{-}$sensing ISMs is their sensitivity to $\mathrm{HCO}_{3}^{-29}$. The problem posed by $\mathrm{HCO}_{3}^{-}$is complex. This ubiquitous intracellular anion is more abundant than $\mathrm{Cl}^{-}$in many cells (e.g. 3-fold higher in mammalian skeletal muscle), and the $\left[\mathrm{HCO}_{3}^{-}\right]$varies greatly depending on $\mathrm{pH}$ and $\mathrm{pCO}_{2}$ changes. Consequently, for Cl-sensing ISMs that are also sensitive to $\mathrm{HCO}_{3}^{-}$there is no simple way to distinguish between real $a_{C l}$ changes, and spurious potential shifts caused by changes in $\left[\mathrm{HCO}_{3}^{-}\right]$. Early $\mathrm{Cl}$-sensing ISMs based on anion exchangers had notoriously poor selectivity for $\mathrm{Cl}^{-}$over $\mathrm{HCO}_{3}^{-15}$. Selectivity for $\mathrm{Cl}^{-}$was greatly improved by using anion-selective carriers, e.g. $\mathrm{Mn}$ (III) porphyrins ${ }^{30}$, but the physiochemical properties of these first-generation carrier electrodes were unfavorable with instability, drift, and non-Nernstian behavior. The high selectivity for $\mathrm{Cl}^{-}$over $\mathrm{HCO}_{3}^{-}$and near-Nernstian behavior of MC3-based solid membrane electrodes ${ }^{22}$ showed tremendous promise for developing a Cl-selective liquid membrane ISM suitable for biological applications.

We measured the sensitivity of MC3-ISMs to interference from changes in $\mathrm{pH}$ or $\left[\mathrm{HCO}_{3}^{-}\right]$, as a test of suitability for these ISMs to be used for intracellular determination of $a_{C l}$. First, we tested for MC3-ISM sensitivity to $\triangle \mathrm{pH}$ from 6.5 to 8.5 , which covers the entire physiologic range of expected cytoplasmic values. In these HEPES-buffered $\mathrm{HCO}_{3}^{-}$- free solutions, a three-point $\mathrm{Cl}^{-}$calibration response $(1,10,100 \mathrm{mM})$ for an MC3-ISM was not affected by a pH shift from 7.4 to 6.5 or from 7.4 to 8.5 (Fig. $4 \mathrm{~A}$, left and right, respectively). Next, we measured the response of MC3-ISMs in constant $10 \mathrm{mM} \mathrm{Cl}^{-}$, a typical value for myoplasmic $\mathrm{Cl}^{-}$in skeletal muscle fibers ${ }^{31,32}$, upon which was imposed step changes in $\mathrm{HCO}_{3}^{-}$from 1 to $50 \mathrm{mM}$ (Fig. 4B), a concentration range far beyond those expected to occur in vivo either in physiological or pathological conditions (i.e. $\sim 13 \mathrm{mM}^{33}$ ). The potentiometric response of MC3-ISMs was completely insensitive to the presence of $\mathrm{HCO}_{3}^{-}$at concentrations as high as $50 \mathrm{mM}$. This is a remarkable feature of the MC3 Cl-selective carrier, and makes MC3-based ISMs the electrode of choice for biological purposes.

Chloride selectivity of the MC3-ISM. The selectivity of the MC3-ISM was assessed for $\mathrm{Cl}^{-}$over various physiologically relevant anions including lactate, phosphate, thiocyanate and bicarbonate. The fixed interference method, as described by IUPAC was used ${ }^{27}$, wherein the concentration of the test interfering anion was held constant at $10 \mathrm{mM}$ (as a Na${ }^{+}$salt), and $\mathrm{V}_{\mathrm{Cl}}$ was measured in solutions with varying $\left[\mathrm{Cl}^{-}\right]$between $100 \mathrm{mM}$ and $100 \mathrm{nM}$. We found that the MC3-ISM response is not significantly affected by the presence of lactate, phosphate, or bicarbonate for $\left[\mathrm{Cl}^{-}\right]$from $100 \mathrm{mM}$ to values as low as $100 \mu \mathrm{M}$ (Fig. 5). On the other hand, the MC3-ISM was almost insensitive to $\mathrm{Cl}^{-}$in the presence thiocyanate (Fig. 5, magenta diamonds). From the data in Fig. 5, we calculated the selectivity coefficient, $K_{C l, X}^{p o t}$, for each test anion (Table 1) which gives a selectivity series: thiocyanate $>\mathrm{Cl} \gg$ bicarbonate $>$ phosphate $\approx$ lactate. Importantly, the MC3-ISM was 125-fold more sensitive to $\mathrm{Cl}^{-}$ than to $\mathrm{HCO}_{3}^{-}$, which explains the lack of an effect for $\mathrm{HCO}_{3}^{-}$in Fig. 4 and confirms the MC3-ISM is suitable for measuring intracellular $a_{C l}$ without interference from fluctuating levels of $\mathrm{HCO}_{3}^{-}$. 
A

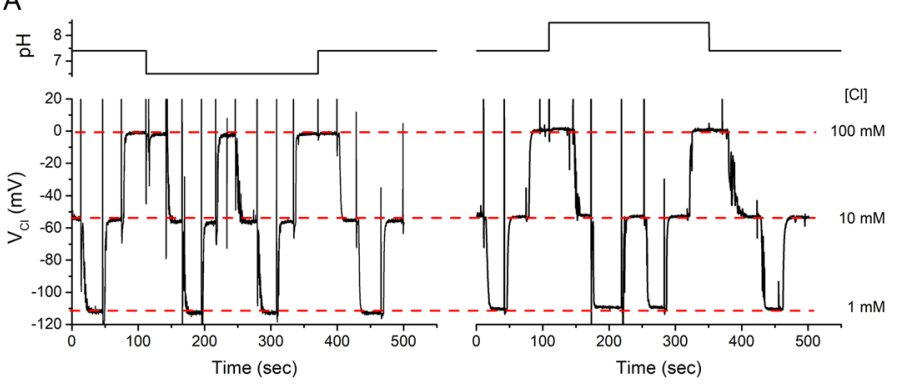

$\mathrm{B}$

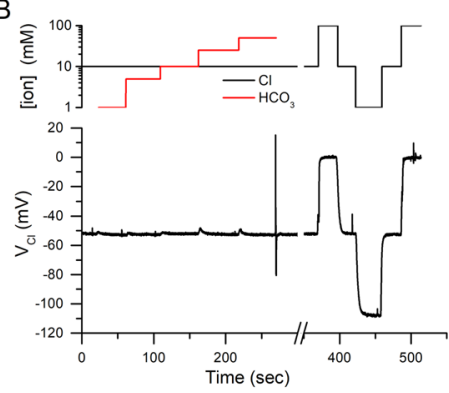

Figure 4. The MC3-ISMs are insensitive to changes in $\mathrm{pH}$ or $\mathrm{HCO}_{3}^{-}$. (A) The $\mathrm{Cl}^{-}$responsiveness of an $\mathrm{MC}^{-}$ ISM was not affected by $\mathrm{pH}$ changes from 6.5 to 8.5 units. The left panel shows the three-point calibration response of $\mathrm{V}_{\mathrm{Cl}}$ for $\left[\mathrm{Cl}^{-}\right]$of 1,10 , and $100 \mathrm{mM}$ is identical at $\mathrm{pH} 7.4$ or $\mathrm{pH} 6.5$ (depicted in the upper plot). Similarly, the right panel shows that the $\mathrm{Cl}^{-}$calibration response was not affected by a pH change from 7.4 to 8.5 units. (B) The left portion of the $\mathrm{V}_{\mathrm{Cl}}$ trace ( 0 to $300 \mathrm{~s}$ ) shows the MC3-ISM response in $10 \mathrm{mM} \mathrm{Cl}^{-}$remained constant, as the $\left[\mathrm{HCO}_{3}^{-}\right]$was varied in step increments from $1 \mathrm{mM}$ to $50 \mathrm{mM}$. The $\mathrm{pH}$ for these $\mathrm{NaCl}: \mathrm{NaHCO}_{3}$ mixtures varied from 7.2 to 7.68 , indicating the $\mathrm{pCO}_{2}$ of the solution had not fully equilibrated with room air. The right part of the record $(>350 \mathrm{sec})$ is the response of this same electrode to changes in $\left[\mathrm{Cl}^{-}\right]$in the absence of $\mathrm{HCO}_{3}^{-}$. The changes in $\mathrm{HCO}_{3}^{-}$and $\mathrm{Cl}^{-}$are depicted in the upper panel by the red and black traces, respectively. For all panels, the different $\left[\mathrm{Cl}^{-}\right]$were obtained by mixing $\mathrm{Cl}$-based and $\mathrm{SO}_{4}$-based solutions (Methods). The "spikes" in the records are due to flux-dependent artifacts during solution switching.

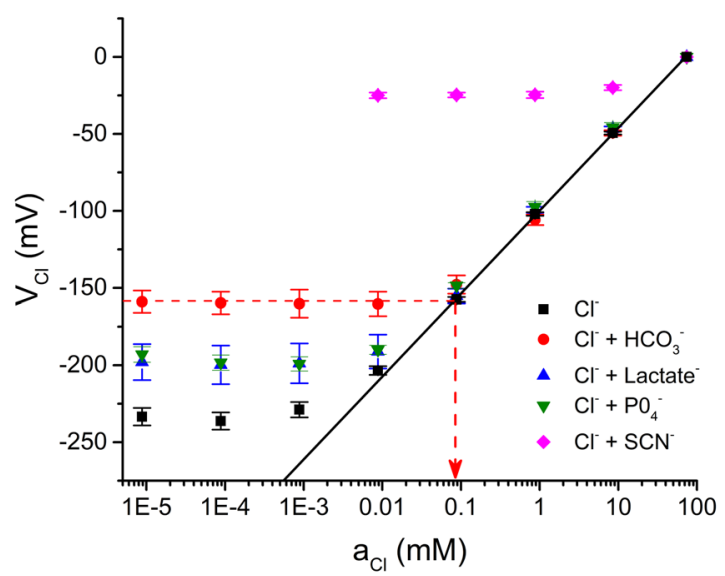

Figure 5. The MC3-ISM is highly selective for $\mathrm{Cl}^{-}$. The MC3-ISM response was measured in solutions prepared by serial dilution of pure $\mathrm{NaCl}$ with no interfering anions $(\mathrm{n}=14$, black squares reproduced from Fig. 2) or for the $\mathrm{NaCl}$ solutions plus $10 \mathrm{mM}$ of the test anion as $\mathrm{Na}^{+}$salts of $\mathrm{HCO}_{3}^{-}(\mathrm{n}=3$, red circles), lactate $\left(\mathrm{n}=3\right.$, blue triangle), $\mathrm{PO}_{4}^{-}\left(\mathrm{n}=3\right.$, green inverted triangle), or $\mathrm{SCN}^{-}(\mathrm{n}=3$, magenta diamond). A linear fit for the pure $\mathrm{NaCl}$ data over a range of $0.1 \mathrm{mM}$ to $100 \mathrm{mM}$ solutions shows a Nernstian response (black line). The cut-off $a_{C l}$ in the presence of an interfering anion was determined by the intersection of limiting asymptote and the Nernstian response, as shown by the example for $\mathrm{HCO}_{3}^{-}$(red dashed line). These values were used to calculate the selectivity coefficient (see Methods).

\begin{tabular}{|l|l|l|l|}
\hline Anion & $\boldsymbol{a}_{\mathrm{Cl}}(\mathrm{mM})$ & $\boldsymbol{K}_{\mathrm{Cl} \text { anion }}^{\text {pot }}$ & $\boldsymbol{l o g}_{\mathbf{1 0}}\left(\boldsymbol{K}_{\text {Cl,anion }}^{\text {pot }}\right)$ \\
\hline $\mathrm{SCN}^{-}$ & $26 \pm 2.1$ & $2.8 \pm 0.23$ & $0.45 \pm 0.035$ \\
\hline $\mathrm{HCO}_{3}^{-}$ & $0.091 \pm 0.010$ & $0.010 \pm 0.0012$ & $-2.0 \pm 0.052$ \\
\hline Lactate & $0.014 \pm 0.0077$ & $0.0015 \pm 0.00085$ & $-3.0 \pm 0.24$ \\
\hline $\mathrm{PO}_{4}^{-}$ & $0.010 \pm 0.0028$ & $0.0011 \pm 0.00031$ & $-3.0 \pm 0.15$ \\
\hline
\end{tabular}

Table 1. Anion selectivity coefficients of the MC3-ISM.

Chloride channel blockers and inhibitors of $\mathrm{Cl}^{-}$co-transporters have little effect on the MC3-ISM response. Chloride-selective electrodes are often sensitive to blockers of $\mathrm{Cl}^{-}$channels or to inhibitors of $\mathrm{Cl}^{-}$co-transporters ${ }^{31,34,35}$. We assessed the MC3-ISM sensitivity for three commonly used $\mathrm{Cl}^{-}$agents, the ClC-1 blocker 9-ACA and the NKCC1 inhibitors bumetanide (BMT) or furosemide (FUR). Our test for 
A
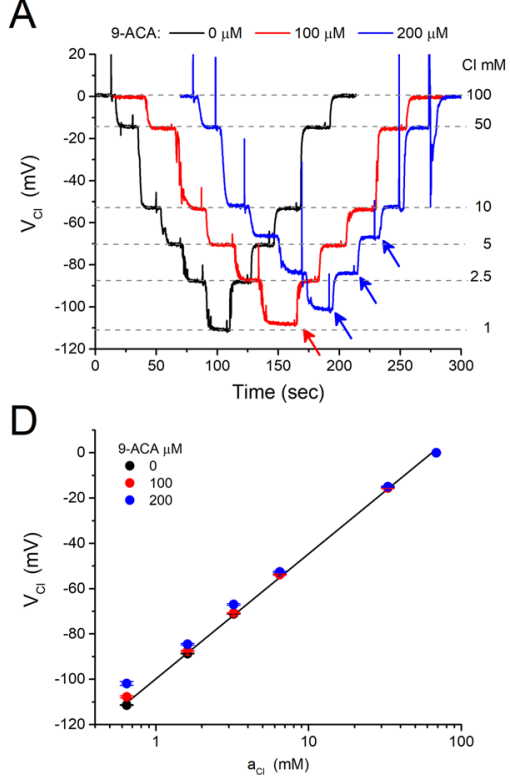

B

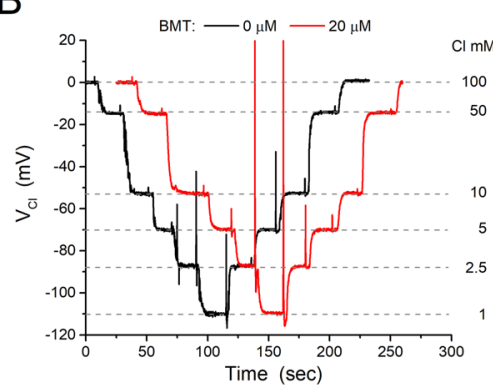

E

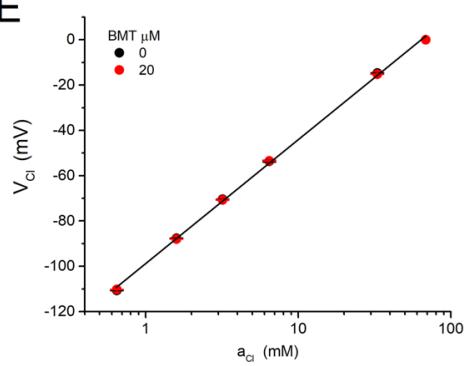

C

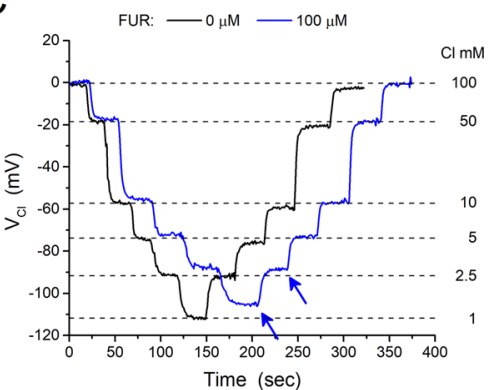

$\mathrm{F}$

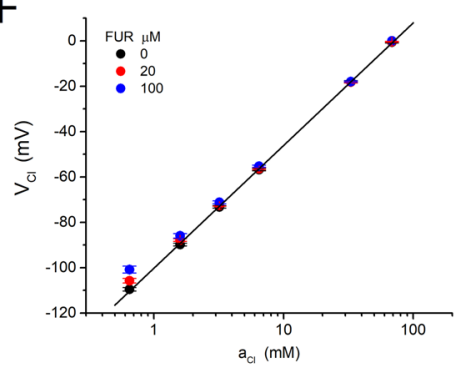

Figure 6. The MC3-ISM response is minimally affected by a $\mathrm{Cl}^{-}$channel blocker and $\mathrm{Cl}^{-}$cotransporter inhibitors. (A) Continuous records of the MCS-ISM potential $\left(\mathrm{V}_{\mathrm{Cl}}\right)$ in response to step changes of $\left[\mathrm{Cl}^{-}\right](1$, $2.5,5,10,50,100 \mathrm{mM}$ ) in the absence (black trace) or presence of $100 \mu \mathrm{M}$ (red trace) and $200 \mu \mathrm{M}$ (blue trace) 9-ACA. Records for each 9-ACA concentration were obtained consecutively for the same MC3-ISM, but were shifted in time and superimposed to facilitate a visual comparison. Arrows indicate detectable differences from the control response in the absence of 9-ACA. (B) Addition of $20 \mu \mathrm{M}$ bumetanide (BMT) did not detectably alter the $\mathrm{V}_{\mathrm{Cl}}$ response of an MC3-ISM. The test protocol and display of the continuous data were the same as in (A). (C) Addition of $100 \mu \mathrm{M}$ furosemide (FUR) did not affect the response for $\mathrm{Cl}^{-}$solutions of $5 \mathrm{mM}$ or greater, and mildly attenuated the response in 2.5 and $1 \mathrm{mM}$ solutions (blue arrows). (D-F) Calibration plots of $\mathrm{V}_{C l}$ as a function of $a_{C l}$ shows that a modest shift of $\mathrm{V}_{\mathrm{Cl}}$ was detectable only for $200 \mu \mathrm{M}$ 9-ACA and at the lowest concentration test solution with $0.1 \mathrm{mM} \mathrm{Cl}^{-}$. For each drug tested $(\mathbf{A}-\mathbf{C})$, similar responses were observed for four different MC3-ISMs. Symbols represent the mean \pm SEM for 4 different MC3-ISMs.

interference was based on detecting a distortion of the Nernstian behavior of an MC3-ISM over an operating range of $1 \mathrm{mM}$ to $100 \mathrm{mM}\left[\mathrm{Cl}^{-}\right]$, while the $\mathrm{Cl}^{-}$agents were added at concentrations typically used for studies of muscle. We found that the MC3-ISM is almost insensitive to 9-ACA (Fig. 6A,D), with a very small effect (reduced $\mathrm{V}_{\mathrm{Cl}}$ response) in $200 \mu \mathrm{M} 9$ - ACA when $\left[\mathrm{Cl}^{-}\right]$was $5 \mathrm{mM}$ or lower. Studies in skeletal muscle that are designed to eliminate the $\mathrm{ClC}-1$ conductance typically use $100 \mu \mathrm{M} 9-\mathrm{ACA}^{36}$. With this concentration of blocker, the $\mathrm{V}_{\mathrm{Cl}}$ response remained Nernstian down to a $\left[\mathrm{Cl}^{-}\right]$of $2.5 \mathrm{mM}$ (the lowest expected physiologically), demonstrating that MC3-ISMs can be used to measure intracellular $a_{C l}$ in studies with 9-ACA. The MC3-ISM response was insensitive to BMT (Fig. 6B,E). At $20 \mu \mathrm{M}$, a concentration in 10-fold excess of that used for complete inhibition of NKCC1, there was no detectable distortion of the MC3-ISM Nernstian behavior over a $\left[\mathrm{Cl}^{-}\right]$range from $1 \mathrm{mM}$ to $100 \mathrm{mM}$. BMT concentrations up to $100 \mu \mathrm{M}$ have been used for some investigations ${ }^{37}$, although in our experience this approaches the solubility limit in physiological saline. Even for a 1:500 dilution of a $50 \mathrm{mM}$ stock BMT solution in DMSO (nominally $100 \mu \mathrm{M}$ BMT), the MC3-ISM was distortion-free down a $\left[\mathrm{Cl}^{-}\right]$of $2.5 \mathrm{mM}$.

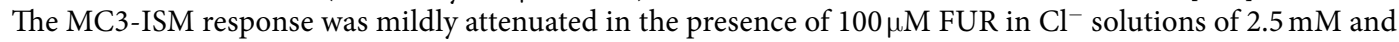
lower (Fig. 6C,F).

Intracellular $\mathrm{Cl}^{-}$activity, $\boldsymbol{a}_{\mathrm{Cl}}^{i}$, measured with an MC3-ISM. We verified the performance of the MCS-ISM as a sensor of intracellular $\mathrm{Cl}^{-}$, by recording $a_{C l}^{i}$ in a skeletal muscle fiber isolated from the flexor digitorum brevis of the mouse. The fiber was impaled with a standard reference electrode to measure the resting potential $\left(\mathrm{V}_{\mathrm{m}}\right.$ Fig. 7, upper panel) and also with a Cl-selective MC3-ISM $\left(\mathrm{V}_{\mathrm{ISM}}\right)$ which reports the combined effect of $\mathrm{V}_{\mathrm{m}}$ and $\mathrm{V}_{\mathrm{Cl}}$. The offset for $\mathrm{V}_{\mathrm{ISM}}=0 \mathrm{mV}$ was set in a calibration solution with $100 \mathrm{mM}\left[\mathrm{Cl}^{-}\right]$. The difference between these two signals, $\mathrm{V}_{\mathrm{Cl}}=\mathrm{V}_{\mathrm{m}}-\mathrm{V}_{\mathrm{ISM}}$ (Fig. 7, lower panel) is proportional to $\log _{10}\left(a_{C l}^{i}\right)$.

In control Tyrode solution $\left(140 \mathrm{mM} \mathrm{Cl}^{-}\right)$, the resting membrane potential was stable $\left(\mathrm{V}_{\mathrm{m}}=-80 \mathrm{mV}\right)$, as was $\mathrm{V}_{\mathrm{Cl}}=-65 \mathrm{mV}$, corresponding to $a_{C l}^{i}=6 \mathrm{mM}$. Upon switching the perfusion to $\mathrm{SO}_{4}$-Tyrode (nominally zero $\mathrm{Cl}^{-}$) the intracellular $a_{C l}^{i}$ exponentially fell to about $1.5 \mathrm{mM}$ because of $\mathrm{Cl}^{-}$efflux through the high resting conductance of ClC-1 channels. These changes are fully reversible, as shown by the recovery of $a_{C l}^{i}$ when the perfusion with $\mathrm{Cl}^{-}$Tyrode was resumed at 500 sec in Fig. 7.

The transient response of $\mathrm{V}_{\mathrm{m}}$ is also consistent with decrease of $a_{C l}^{i}$, followed by recovery ${ }^{4}$. At the onset of $\mathrm{Cl}$-free Tyrode solution (Fig. 7, $80 \mathrm{sec}$ ), $\mathrm{V}_{\mathrm{m}}$ depolarized because the equilibrium potential for $\mathrm{Cl}^{-}$suddenly shifted from about $-77 \mathrm{mV}$ to a positive value. Intracellular $\mathrm{Cl}^{-}$content then declined over the next $30 \mathrm{~s}$, which shifted $\mathrm{E}_{\mathrm{Cl}}$ to more negative potentials and caused $\mathrm{V}_{\mathrm{m}}$ to relax back toward $-80 \mathrm{mV}$. When extracellular $\mathrm{Cl}^{-}$is suddenly 


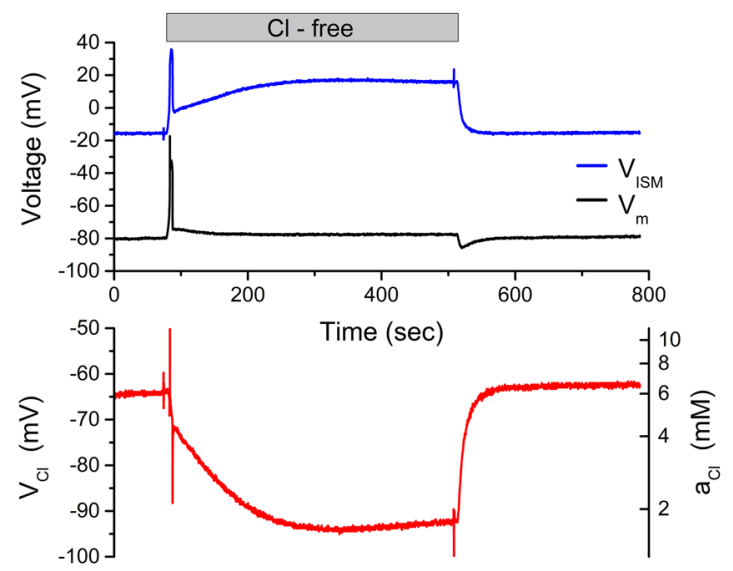

Figure 7. Myoplasmic $a_{C l}^{i}$ measured with an MC3-ISM. Simultaneous intracellular recordings of membrane potential ( $\mathrm{V}_{\mathrm{m}}$, black trace) and the MC3-ISM response ( $\mathrm{V}_{\mathrm{ISM}}$, blue trace) were obtained by impaling a dissociated fiber from the flexor digitorum brevis muscle (upper panel). Digital subtraction $\left(\mathrm{V}_{\mathrm{m}}-\mathrm{V}_{\mathrm{ISM}}\right)$ was performed to calculate the red trace in the lower panel, representing both linear changes of $\mathrm{V}_{\mathrm{Cl}}$ (left ordinate) as a function of time and logarithmic changes in $a_{C l}^{i}$ as a function of time (right ordinate). At $80 \mathrm{~s}$, the bath was exchanged to $\mathrm{Cl}$-free Tyrode solution, and then back to normal Tyrode $(150 \mathrm{mM} \mathrm{Cl})$ at $500 \mathrm{~s}$.

restored (Fig. 7, $500 \mathrm{sec}$ ), $\mathrm{V}_{\mathrm{m}}$ had a hyperpolarizing undershoot because intracellular $a_{C l}^{i}$ was now lower than baseline. As $a_{C l}^{i}$ increased back to the normal basal level, $\mathrm{V}_{\mathrm{m}}$ relaxes to the initial value of $-80 \mathrm{mV}$. Similar responses were observed in 8 additional muscle fibers.

\section{Discussion}

The development of a highly-selective and sensitive chloride sensor in polymeric membrane electrodes, based on the preorganized macrocyclic Lewis acid MC-3 as the anion carrier ${ }^{22}$, was a major technological advance. Prior electrode designs using anion exchangers (e.g. TBT or TDMAC) lacked selectivity, which in these electrodes was dominated by anion lipophilicity (Hofmeister series). Improved $\mathrm{Cl}^{-}$selectivity was achieved with metalloporphyrin carriers (e.g. $\mathrm{Mn}(\mathrm{III})$, chloride ionophore I Sigma-Aldrich), but interference from $\mathrm{HCO}_{3}^{-}$was still problematic, $\log _{1 \rho}\left(K_{\mathrm{Cl}, \mathrm{HCO} 3}^{\text {pot }}\right)=-1.4$, for intracellular determination of $a_{C l}{ }^{38}$. Excellent selectivity for $\mathrm{Cl}^{-}$over $\mathrm{HCO}_{3}^{-}$was achieved with neutral carriers comprised of Lewis acids containing two or more covalently bonded $\mathrm{Hg}$ (II) ${ }^{39}$ (e.g. chloride ionophore II, Sigma-Aldrich), but these compounds were suboptimal for liquid membrane ion-selective microelectrodes because of sluggish response times $\left(t_{90 \%} \sim 10 \mathrm{~s}\right)$, electrical instability with drift and non-Nernstian responses, or poor solubility in NPOE. In contrast, MC-3 is chemically stable, and MC-3 based polymeric membrane electrodes have more consistent Nernstian responses, high selectivity for $\mathrm{Cl}^{-}$, and faster settling times of a few seconds. The MC3 ionophore represents a unique platform for chloride sensing. These properties stem from the molecular architecture of this structure which includes a precise triatomic arrangement of $\mathrm{Hg}$ (II) sites separated by rigid ortho-carboranyl boron-rich cluster ligands. Such a trinuclear metal receptor arrangement allows MC3 to bind anions in a multivalent fashion. Furthermore, electron-withdrawing nature of the C-bound ortho-carborane clusters, similar in magnitude to the perfluoroaryl substitutents ${ }^{40,41}$, enhances the Lewis acidity of the $\mathrm{Hg}(\mathrm{II})$ centers critical to the anion binding. Finally, the sterically encumbering nature of the boron cluster ligands enhances the kinetic stability of the corresponding organometallic complex and creates a well-defined pocket around the $\mathrm{Hg}$-based centers modulating the anion binding selectivity.

We now show that the advantages of MC-3 based polymeric membrane electrodes can be realized in a liquid membrane microelectrode form factor. Following from the design of the MC-3 electrodes in PVC membranes ${ }^{22}$, we used NPOE as the liquid organic phase in our ISMs and no other plasticizers were tested. Just as with the PVC membrane electrodes, the potentiometric response to $\mathrm{Cl}^{-}$with MC-3 alone was sub-Nernstian (Fig. 1), and doping the liquid membrane with a lipophilic cationic additive (2.5\% TDMAC) markedly increased the ISM sensitivity to near-Nernstian behavior $(54.3 \mathrm{mV} /$ decade). Increased amounts of cationic additive in PVC membrane electrodes extended the linear range for high $a_{C l}$ to about $100 \mathrm{mM}$, but with a cost of slightly reduced selectivity for $\mathrm{Cl}^{-}$over other anions ${ }^{22}$. Since our ISMs already had linear responses up to the highest concentration of the calibration solution (nominally $100 \mathrm{mM}$ mixture, calculated $a_{C l}=68.5 \mathrm{mM}$ ), we did not test higher amounts of additive. Moreover, in a physiological context the expected intracellular $a_{C l}$ is in the range of 3 to $20 \mathrm{mM}$.

The potentiometric responses of MC-3 ISMs were remarkably consistent and stable over long recording periods. Except for the occasional failure in the fabrication of an ISM (e.g. air bubble at the liquid membrane/aqueous electrolyte interface), the variability was exceptionally small in the slope of the linear response range $(0.1 \mathrm{mM}$ to $100 \mathrm{mM}$ ). A sample of $24 \mathrm{MC}-3$ ISMs with an average slope of $54.6 \mathrm{mV} /$ decade had a standard deviation of only $0.9 \mathrm{mV} /$ decade and a range of 52.9 to $56.0 \mathrm{mV} /$ decade. By comparison, a sample of 62 ISMs constructed with the "improved" Corning 477913 chloride ionophore was reported to have a mean slope of $52.8 \mathrm{mV} /$ decade with a standard deviation of $5.1 \mathrm{mV} /$ decade and the range of values extended from 35 to $64 \mathrm{mV} / \mathrm{decade}^{42}$. The potentiometric response of MC-3 ISMs was stable with no significant drift over ten minutes or more, as shown 
by examples in several Figs. $(2-4,6)$. Moreover, the intracellular response recorded from a skeletal muscle fiber was also stable, as shown by the return to the baseline value after recovery from a $10 \mathrm{~min}$ exposure to $\mathrm{Cl}$-free conditions (Fig. 7).

The slow electrical response time of Cl-selective ISMs has been a limiting factor for use of some ionophores. The problem arises from the high resistivity of immiscible liquid membranes with neutral ion carriers in combination with the capacitance of the glass pipette. While reducing the ISM tip resistance with cationic additives, choice of the ionophore, and optimization of the liquid membrane thickness may be used to improve performance, the $10 \%$ to $90 \%$ response time was reported to be as long as $41 \mathrm{sec}$ for $\mathrm{Mn}$ (III) porphyrin Cl-selective $\mathrm{ISMs}^{38}$. For macroscopic MC-3 electrodes in PVC membranes, a more favorable rise time of about $10 \mathrm{sec}$ was observed $^{22}$. In our MC-3 ISMs the $10 \%$ to $90 \%$ response time was about $3 \mathrm{sec}$ (Fig. 3), which is sufficient to monitor changes of intracellular $a_{C l}$ in muscle fibers that typically occur over tens of seconds to minutes.

The most important advantage of MC-3 ISMs is the high selectivity for $\mathrm{Cl}$ over other anions, especially $\mathrm{HCO}_{3}^{-}$. Historically, the $\mathrm{Cl}^{-}$ISMs used in several landmark papers showing intracellular $a_{C l}$ in muscle and heart is higher than expected from passive electrodiffusion were based on proprietary $\mathrm{Cl}^{-}$ionophores from Corning (477315 and later 477913) that had substantial interference from $\mathrm{HCO}_{3}^{-29,31,32}$. This limitation was compounded by the composition of the intracellular milieu, where $a_{C l}$ is typically $4 \mathrm{mM}$, and $\mathrm{HCO}_{3}^{-}$is more abundant at 14 to $18 \mathrm{mM}$. With a Corning 477913 ISM, the selectivity for $\mathrm{Cl}_{\text {over }} \mathrm{HCO}_{3}^{-}$was about 8:1, corresponding to a selectivity coefficient $\log _{10}\left(K_{\mathrm{Cl}, \mathrm{HCO} 3}^{\text {pot }}\right)$ of $-0.9^{38}$. With this degree of $\mathrm{HCO}_{3}^{-}$interference, a true $a_{\mathrm{Cl}}$ of $4 \mathrm{mM}$ in combination with an $a_{\mathrm{HCO} 3}$ of $15 \mathrm{mM}$ would cause a $9.3 \mathrm{mV}$ error in the potentiometric value of the $\mathrm{Cl}^{-} \mathrm{ISM}$, corresponding to an overestimate of $a_{C l}$ as $5.9 \mathrm{mM}$. In contrast, the high Cl-selectivity we observed for an MC3-ISM, $\log _{10}\left(K_{\mathrm{Cl}, \mathrm{HCO} 3}^{\text {pot }}\right)=-2$, would result in only a $0.9 \mathrm{mV}$ error with an estimated value of $a_{C l}=4.14 \mathrm{mM}$. Insensitivity to $\mathrm{HCO}_{3}^{-}$(Fig. 4) is also important because intracellular $\mathrm{pH}$ often changes or is intentionally manipulated during a study. The accompanying fluctuations of intracellular $a_{\mathrm{HCO} 3}$ would render the potentiometric response uninterpretable for a poorly selective $\mathrm{Cl}^{-}$ISM. Sensitivity to $\mathrm{pH}$ is also a limitation for genetically encoded $\mathrm{Cl}$ sensors based on YFP variants, which has led to the development of ratiometric dual-sensor fluorescent proteins (ClopHensor) to monitor both [Cl] and $\mathrm{pH}$ simultaneously ${ }^{43}$.

Another selectivity-based limitation of earlier $\mathrm{Cl}^{-}$ISMs was interference from drugs used to block $\mathrm{Cl}^{-}$channels (e.g. 9-ACA) or to inhibit $\mathrm{Cl}^{-}$exchangers and cotransporters (e.g. SITS, bumetanide, furosemide). These compounds are often used in studies of $\mathrm{Cl}$ transport, where drug-dependent changes in extracellular and intracellular $\mathrm{Cl}^{-}$activity are measured with ISMs. These inhibitors have high lipid solubility and are anions at physiologic $\mathrm{pH}$, and so not surprisingly, substantial anion interference occurs for ISMs using poorly selective ionophores such as Corning 477413. For example, furosemide at $100 \mu \mathrm{M}$ caused nonlinear potentiometric responses for $a_{C l} \leq 30 \mathrm{mM}$, with a corresponding selectivity coefficient of $K_{\mathrm{Cl}, \mathrm{Fu}}^{\mathrm{Pot}}=157^{35}$. We tested three drugs that inhibit $\mathrm{Cl}^{-}$ transport: furosemide, bumetanide, and 9-AC. In furosemide, we detected mild deviations from linear Nernstian behavior for MC3-ISM electrodes when $a_{C l} \leq 1.6$ which is 20 -fold lower than for Corning 477413 (Fig. 6C,F). In contrast, the potentiometric response of the MC3-ISM over the entire range of test solutions ([Cl] from 1 to $100 \mathrm{mM}$ ) was not affected by $20 \mu \mathrm{M}$ bumetanide (Fig. $6 \mathrm{~B}$ ), which is ten times the $\mathrm{IC}_{50}$ to inhibit the Na-K-2Cl 1 cotransporter. For the $\mathrm{ClC}-1$ channel blocker, we detectable interference in $200 \mu \mathrm{M} 9$-ACA when [Cl] $<10 \mathrm{mM}$ (Fig. 6A). Studies in skeletal muscle typically use $100 \mu \mathrm{M} 9$-ACA, and at this lower concentration we detected a change in the MC3-ISM response only for [Cl] $<2.5 \mathrm{mM}$. Overall, the MC3-ISM is highly selective for $\mathrm{Cl}$ with a linear Nernstian response over the biologically meaningful operating range of 1 to $100 \mathrm{mM}$, with no interference from endogenous anions $\left(10 \mathrm{mM} \mathrm{HCO}_{3}^{-}, \mathrm{PO}_{4}^{-}\right.$, or lactate) or bumetanide and very modest effects in high-dose 9-ACA well above the $\mathrm{IC}_{50}$.

Finally, we demonstrate that the MC3-ISM reliably measures $a_{C l}$ in a biological context, the intracellular activity in an isolated skeletal muscle fiber (Fig. 7). The response to an external Cl-free challenge is a stringent test of the MC3-ISM because the resulting decrease of intracellular $a_{C l}$ would reveal effects from interfering intracellular anions or other sources of distortion as an attenuation of the change in the potentiometric signal. The response in Fig. 7 clearly shows a large response for $\mathrm{V}_{\mathrm{Cl}}=-\left(\mathrm{V}_{\mathrm{MC} 3-\mathrm{ISM}}-\mathrm{V}_{\text {ref }}\right)$, corresponding to a decrease of intracellular $a_{C l}$ to less than $2 \mathrm{mM}$. The record in Fig. 7 also shows the high quality of the signal-to-noise for measuring intracellular $a_{C l}$, as well as the stability of the response with no significant drift and a return to the same baseline when external $\mathrm{Cl}$ is restored 10 minutes later. Measurement of intracellular $a_{C l}$ is also of great interest in studies of the nervous system because the Nernst potential for $\mathrm{Cl}^{-}$determines the postsynaptic response to activation of glycine and $\mathrm{GABA}_{\mathrm{A}}$ receptors. Moreover, intracellular $\mathrm{Cl}^{-}$varies over time, ranging from 3 to $20 \mathrm{mM}$ or higher. Neuronal intracellular $\mathrm{Cl}^{-}$is high in the immature brain, in part due to activity of $\mathrm{NKCC1}$ that promotes $\mathrm{Cl}^{-}$influx, and so receptor activation elicits post-synaptic depolarization (i.e. excitation). With development, NKCC1 decreases and is replaced by KCC that promotes $\mathrm{Cl}^{-}$efflux ${ }^{3,44,45}$. The reduced intracellular $\mathrm{Cl}^{-}$shifts the Nernst potential for $\mathrm{Cl}^{-}$ below the resting potential and receptor activation now produces hyperpolarization (inhibition). Derangements of the $\mathrm{Cl}^{-}$gradient in the neurons have been implicated in epilepsy ${ }^{46}$ and in anomalous regulation of cell volume that drives proliferation and migration of gliomas ${ }^{47}$. The MC3-ISM offers an improved approach for measuring somatic $a_{C l}$ for the determination of basal levels and changes that may occur over seconds to minutes - for example in response to inhibition of specific transporters. Of course alternative methods, such as dye fluorescence lifetime ${ }^{9}$ or genetically encoded Cl-sensors ${ }^{10}$, are required to measure local $a_{C l}$ changes within diffusion-restricted spaces in out in the dendrites or for fast transients less than $3 \mathrm{sec}$.

Received: 6 August 2019; Accepted: 20 November 2019;

Published online: 11 December 2019 


\section{References}

1. Shcheynikov, N. et al. Intracellular $\mathrm{Cl}^{-}$as a signaling ion that potently regulates $\mathrm{Na}^{+} / \mathrm{HCO}_{3}{ }^{-}$transporters. Proc Natl Acad Sci USA 112, E329-337, https://doi.org/10.1073/pnas.1415673112 (2015).

2. Stauber, T., Weinert, S. \& Jentsch, T. J. Cell biology and physiology of CLC chloride channels and transporters. Comprehensive Physiology 2, 1701-1744, https://doi.org/10.1002/cphy.c110038 (2012).

3. Rivera, C. et al. The $\mathrm{K}^{+} / \mathrm{Cl}^{-}$co-transporter KCC2 renders GABA hyperpolarizing during neuronal maturation. Nature 397, 251-255, https://doi.org/10.1038/16697 (1999).

4. Hodgkin, A. L. \& Horowitcz, P. The influence of potassium and chloride on the membrane potential of single muscle fibres. J. Physiol. 148, 127-160 (1959).

5. Pedersen, T. H., de Paoli, F. \& Nielsen, O. B. Increased excitability of acidified skeletal muscle: role of chloride conductance. J Gen Physiol 125, 237-246 (2005).

6. Mi, W., Wu, F., Quinonez, M., DiFranco, M. \& Cannon, S. C. Recovery from acidosis is a robust trigger for loss of force in murine hypokalemic periodic paralysis. J Gen Physiol 151, 555-566, https://doi.org/10.1085/jgp.201812231 (2019).

7. Wu, F., Mi, W. \& Cannon, S. C. Bumetanide prevents transient decreases in muscle force in murine hypokalemic periodic paralysis. Neurology 80,1110-1116, https://doi.org/10.1212/WNL.0b013e3182886a0e (2013).

8. Tsien, R. Y. Intracellular measurements of ion activities. Annu Rev Biophys Bioeng 12, 91-116, https://doi.org/10.1146/annurev. bb.12.060183.000515 (1983).

9. Gensch, T., Untiet, V., Franzen, A., Kovermann, P. \& Fahlke, C. In Advanced Time-Correlated Single Photon Counting Applications (ed. Becker, W.) 189-211 (Springer International Publishing, 2015).

10. Arosio, D. \& Ratto, G. M. Twenty years of fluorescence imaging of intracellular chloride. Front Cell Neurosci 8, 258, https://doi. org/10.3389/fncel.2014.00258 (2014).

11. Standen, N. B. G., Gray, P. T. A. \& Whitakwer, M. J. Microelectrode techniques, 137-167 (The Company of Biologists Limited, 1987).

12. Lee, S. K., Boron, W. F. \& Parker, M. D. Monitoring ion activities in and around cells using ion-selective liquid-membrane microelectrodes. Sensors (Basel) 13, 984-1003, https://doi.org/10.3390/s130100984 (2013).

13. Fedirko, N., Svichar, N. \& Chesler, M. Fabrication and use of high-speed, concentric $\mathrm{h}^{+}$- and $\mathrm{Ca}^{2+}$-selective microelectrodes suitable for in vitro extracellular recording. J Neurophysiol 96, 919-924, https://doi.org/10.1152/jn.00258.2006 (2006).

14. Messerli, M. A., Collis, L. P. \& Smith, P. J. Ion trapping with fast-response ion-selective microelectrodes enhances detection of extracellular ion channel gradients. Biophys J 96, 1597-1605, https://doi.org/10.1016/j.bpj.2008.11.025 (2009).

15. Alvarez-Leefmans, F. J., Giraldez, F. \& Russell, J. M. In Chloride CHannels and Carriers in Nerve, Muscle, and Glial Cells (eds Alavarez-Leefmans, F. J. \& Russell, J. M.) Ch. 1, 3-66 (Springer, 1990).

16. Davis, A. P., Sheppard, D. N. \& Smith, B. D. Development of synthetic membrane transporters for anions. Chem Soc Rev 36, 348-357, https://doi.org/10.1039/b512651g (2007).

17. Share, A. I. et al. Chloride anion transporters inhibit growth of methicillin-resistant Staphylococcus aureus (MRSA) in vitro. Chem Commun (Camb) 52, 7560-7563, https://doi.org/10.1039/c6cc03645g (2016).

18. Shen, B., Li, X., Wang, F., Yao, X. \& Yang, D. A synthetic chloride channel restores chloride conductance in human cystic fibrosis epithelial cells. PLoS One 7, e34694, https://doi.org/10.1371/journal.pone.0034694 (2012).

19. Choi, Y. R., Chae, M. K., Kim, D., Lah, M. S. \& Jeong, K. S. Synthetic chloride transporters with the binding mode observed in a ClC chloride channel. Chem Commun (Camb) 48, 10346-10348, https://doi.org/10.1039/c2cc35743g (2012).

20. Li, H. et al. Efficient, non-toxic anion transport by synthetic carriers in cells and epithelia. Nat Chem 8, 24-32, https://doi. org/10.1038/nchem.2384 (2016).

21. McNally, B. A. et al. Structure-activity relationships in cholapod anion carriers: enhanced transmembrane chloride transport through substituent tuning. Chemistry 14, 9599-9606, https://doi.org/10.1002/chem.200801163 (2008).

22. Badr, I. H., Diaz, M., Hawthorne, M. F. \& Bachas, L. G. Mercuracarborand "anti-crown ether"-based chloride-sensitive liquid/ polymeric membrane electrodes. Anal Chem 71, 1371-1377 (1999).

23. Yang, X., Zheng, Z., Knobler, C. B. \& Hawthorne, M. F. “Anti-Crown” chemistry: Synthesis of [9]mercuracarborand-3 and the crystal structure of its acetonitrile complexes. J. Am. Chem. Soc. 115, 193-195 (1993)

24. Parsons, R. Handbook of electrochemical constant, 20-28 (Butterworth, 1959).

25. Debye, P. \& Hückel, E. The theory of electrolytes I. Lowering of freezing point and related phenomena. Physikalische Zeitschrift 24, 185-206 (1923).

26. Woods, C. E., Novo, D., DiFranco, M. \& Vergara, J. L. The action potential-evoked sarcoplasmic reticulum calcium release is impaired in mdx mouse muscle fibres. J Physiol 557, 59-75 (2004).

27. Umezawa, Y., Buhlmann, P., Umezawa, J., Tohda, K. \& Ameniya, S. Potentiometric selectivity coefficients of ion-selective electrodes. Pure Applied Chemistry 72, 1851-2082 (2000).

28. Habela, C. W., Ernest, N. J., Swindall, A. F. \& Sontheimer, H. Chloride accumulation drives volume dynamics underlying cell proliferation and migration. J Neurophysiol 101, 750-757, https://doi.org/10.1152/jn.90840.2008 (2009).

29. Bolton, T. B. \& Vaughan-Jones, R. D. Continuous direct measurement of intracellular chloride and pH in frog skeletal muscle. $J$ Physiol 270, 801-833 (1977).

30. Huser, M. et al. Transport properties of anion-selective membranes based on cobyrinates and metaloporphyrin complexes as ionophores. Chimica Acta 73, 1481-1496 (1990).

31. Aickin, C. C., Betz, W. J. \& Harris, G. L. Intracellular chloride and the mechanism for its accumulation in rat lumbrical muscle. J Physiol 411, 437-455 (1989).

32. Vaughan-Jones, R. D. Non-passive chloride distribution in mammalian heart muscle: micro-electrode measurement of the intracellular chloride activity. J Physiol 295, 83-109 (1979).

33. Khuri, R. N., Agulian, S. K. \& Bogharian, K. K. Intracellular bicarbonate of skeletal muscle under different metabolic states. Am J Physiol 230, 228-232 (1976).

34. Messerli, M. A., Kurtz, I. \& Smith, P. J. Characterization of optimized $\mathrm{Na}^{+}$and $\mathrm{Cl}^{-}$liquid membranes for use with extracellular, selfreferencing microelectrodes. Anal Bioanal Chem 390, 1355-1359, https://doi.org/10.1007/s00216-007-1804-z (2008).

35. Chao, A. C. \& Armstrong, W. M. Cl(-)-selective microelectrodes: sensitivity to anionic $\mathrm{Cl}^{-}$transport inhibitors. Am J Physiol 253, C343-347, https://doi.org/10.1152/ajpcell.1987.253.2.C343 (1987).

36. Palade, P. T. \& Barchi, R. L. On the inhibition of muscle membrane chloride conductance by aromatic carboxylic acids. The Journal of general physiology 69, 879-896 (1977).

37. Glykys, J. et al. Local impermeant anions establish the neuronal chloride concentration. Science 343, 670-675, https://doi. org/10.1126/science.1245423 (2014).

38. Kondo, Y., Buhrer, T., Seiler, K., Fromter, E. \& Simon, W. A new double-barrelled, ionophore-based microelectrode for chloride ions. Pflugers Arch 414, 663-668 (1989).

39. Rothmaier, M. \& Simon, W. Chloride-selective electrodes based on mercury organic compounds as neutral carriers. Analytica Chimica Acta 271, 135-141 (1993).

40. Spokoyny, A. M. et al. A coordination chemistry dichotomy for icosahedral carborane-based ligands. Nat Chem 3, 590-596, https:// doi.org/10.1038/nchem.1088 (2011).

41. Yruegas, S., Axtell, J. C., Kirlikovali, K. O., Spokoyny, A. M. \& Martin, C. D. Synthesis of 9-borafluorene analogues featuring a threedimensional 1,1'-bis(o-carborane) backbone. Chem Commun (Camb) 55, 2892-2895, https://doi.org/10.1039/c8cc10087j (2019). 
42. Baumgarten, C. M. An improved liquid ion exchanger for chloride ion-selective microelectrodes. Am J Physiol 241, C258-263, https://doi.org/10.1152/ajpcell.1981.241.5.C258 (1981).

43. Arosio, D. et al. Simultaneous intracellular chloride and pH measurements using a GFP-based sensor. Nat Methods 7, 516-518, https://doi.org/10.1038/nmeth.1471 (2010).

44. Kakazu, Y., Akaike, N., Komiyama, S. \& Nabekura, J. Regulation of intracellular chloride by cotransporters in developing lateral superior olive neurons. J Neurosci 19, 2843-2851 (1999).

45. Kahle, K. T. et al. Roles of the cation-chloride cotransporters in neurological disease. Nature clinical practice 4, 490-503, https://doi. org/10.1038/ncpneuro0883 (2008).

46. Glykys, J. et al. Chloride Dysregulation, Seizures, and Cerebral Edema: A Relationship with Therapeutic Potential. Trends Neurosci 40, 276-294, https://doi.org/10.1016/j.tins.2017.03.006 (2017).

47. Ransom, C. B., O’Neal, J. T. \& Sontheimer, H. Volume-activated chloride currents contribute to the resting conductance and invasive migration of human glioma cells. J Neurosci 21, 7674-7683 (2001).

\section{Acknowledgements}

This work was supported by grants AR63182, AR42703 (NIAMS/NIH) and RG-381149 (MDA) to SC, and R21-AR067422 (NIH) to MD. A.M.S. thanks the UCLA Department of Chemistry and Biochemistry for start-up funds and 3M for a Non-Tenured Faculty Award, the Alfred P. Sloan Foundation for a Fellowship in Chemistry, Research Corporation for Science Advancement (RCSA) for a Cottrell Scholar Award, and the NIH for a Maximizing Investigators Research Award (MIRA, R35GM124746). R.M.D. was supported by a National Defense Science and Engineering Graduate Fellowship. We thank Dr. J.L. Padrino (Mount Sinai Medical Center) for kindly sharing his knowhow on the fabrication of ISM's. Compound-3 was a kind gift from Dr. Dan Yang (The University of Hong Kong, P.R. China); Compound-4H was a kind gift from Dr. Kyu-Sung Jeong (Yonsei University, Korea); and compound-13 and compound-3 were a kind gift from Dr. Anthony Davis (University of Bristol, UK).

\section{Author contributions}

The experimental design was conceived by M.D., S.C. and A.S. MC3 was synthesized by R.D. Measurement of ISM responses were performed by M.Q. and M.D. The paper was written by M.D., S.C. and A.S. All authors reviewed the final manuscript and approved the content.

\section{Competing interests}

The authors declare no competing interests.

\section{Additional information}

Correspondence and requests for materials should be addressed to S.C.C.

Reprints and permissions information is available at www.nature.com/reprints.

Publisher's note Springer Nature remains neutral with regard to jurisdictional claims in published maps and institutional affiliations.

(c) (i) Open Access This article is licensed under a Creative Commons Attribution 4.0 International License, which permits use, sharing, adaptation, distribution and reproduction in any medium or format, as long as you give appropriate credit to the original author(s) and the source, provide a link to the Creative Commons license, and indicate if changes were made. The images or other third party material in this article are included in the article's Creative Commons license, unless indicated otherwise in a credit line to the material. If material is not included in the article's Creative Commons license and your intended use is not permitted by statutory regulation or exceeds the permitted use, you will need to obtain permission directly from the copyright holder. To view a copy of this license, visit http://creativecommons.org/licenses/by/4.0/.

(c) The Author(s) 2019 